\author{
KEVIN MOHEE ${ }^{1}$, AMALAN KARTHIGEYAN ${ }^{1}$, \\ STEPHEN B. WHEATCROFT ${ }^{2}$, KATARZYNA KUCHARSKA ${ }^{3}$
}

\title{
Cardiac abnormalities in anorexia nervosa inpatients - a retrospective study
}

\begin{abstract}
Introduction. Anorexia nervosa (AN) is a life-threatening condition, with significant risk of death due to cardiac abnormalities.

Aim. The aim of this study was to investigate for QTc interval or heart rate (HR) abnormalities in AN patients and any correlation between BMI, HR and QTc interval at baseline and at completion of treatment.

Material and methods. 30 patients (29 females, 1 male) aged 16 to 45 years with a diagnosis of AN were retrospectively analyzed from January 2012 to September 2014. An ECG, biochemical tests, BMI and clinical assessment were performed on admission. ECG and BMI were also repeated at discharge.

Results. A paired t-test was used to compare two sets of scores that come from the same participants on both admission and discharge. The mean baseline BMI was $14.8+/-4 \mathrm{~kg} / \mathrm{m}^{2}$, baseline HR was $53.4+/-16$ bpm and QTc interval 416 +/- $40 \mathrm{~ms}$. At discharge, mean BMI was $18.7+/-2 \mathrm{~kg} / \mathrm{m}^{2}$, HR was $73+/-11 \mathrm{bpm}$ and QTc interval $402+/-34$. The mean QTc interval was decreased by $14 \mathrm{~ms}$ and the HR increased by 19 beats $/ \mathrm{min}$. A Wilcoxon test showed that the treatment course did not elicit a statistically significant change in HR score in individuals with $A N(Z=-4, p=0.000)$. Pearson correlations showed that patients with a higher magnesium had lower heart rate on admission $(\mathrm{r}=-0.61 ; \mathrm{p}=0.002)$.

Conclusion. Further exploration is needed in a larger population to investigate for etiology and medical management of cardiac abnormalities in AN.
\end{abstract}

Keywords: cardiac abnormalities, QTc, bradycardia, anorexia nervosa.

DOI: $10.1515 /$ pjph-2015-0038

\section{INTRODUCTION}

Anorexia nervosa (AN) is a life-threatening mental disorder characterized by refusal to maintain body weight at or above a minimally normal level for age and height, ardent fear of gaining weight or becoming fat and disturbed body image [1]. The etiology of AN is unclear but a key role is played by the complex interplay among biologic, genetic, psychological and sociocultural factors [2]. AN has a prevalence of $0.9-2.2 \%$ among young women and has the highest mortality rate among psychiatric disorders [3]. Two forms of AN are described in the DSM-V, the restrictive subtype (AN-R) and the binge-eating/purging subtype (AN-BP) [1].Cardiovascularcomplications account for atleast a third of all deaths in sufferers of AN. These complications occur in $80 \%$ of cases and comprise bradycardia, hypotension, arrhythmias, QTc prolongation and sudden death [4]. The consequences of $\mathrm{AN}$ in the form of malnutrition and food restriction lead to increased vagal tone, bradycardia, orthostatic hypotension, syncope, congestive heart failure and death as a result of cardiac complications [4].

\section{AIM}

The aim of this study was to investigate the prevalence of ECG based abnormalities in patients with AN and the association between BMI and ECG abnormalities at admission to a treatment facility and after completion of treatment.

\section{MATERIAL AND METHODS}

30 inpatients with anorexia nervosa (29 females, 1 male), age range 16-45, (18 restricting and 3 binge-purge type) fulfilling both International Classification of Diseases (ICD-10) and Diagnostic and Standardised Measures IV or V (DSM IV or DSM V) criteria were recruited from the Specialist Eating Disorder Service (Table 1). Consensus diagnoses were obtained from Consultant Psychiatrist/Master ED practitioner who assessed the patients in clinical interviews.

A 12 lead electrocardiogram (ECG), biochemical tests, DEXA scan, and BMI were performed on admission and regularly repeated as per The National Institute for Health and Care Excellence (NICE) and Management of Really

\footnotetext{
${ }^{1}$ Rharian Fields, Specialist Eating Disorder Unit, The Gardens, 2nd Avenue, Grimsby, UK

${ }^{2}$ Division of Cardiovascular \& Diabetes Research, Leeds Multidisciplinary Cardiovascular Research Centre, University of Leeds, Leeds, UK

${ }^{3}$ Institute of Psychiatry and Neurology, Warsaw, Poland
} 
Sick Patients with Anorexia Nervosa (MARSIPAN) guidelines [5,6]. A long QTc interval was defined as QTc $>440 \mathrm{~ms}$. This value was taken as an arbitrary although commonly used upper limit of normal.

\section{Statistical analyses}

Statistical analyses were performed using SPSS 20.0 statistical software for Microsoft Windows. A paired t-test was used to compare two sets of scores that come from the same participants on both admission and discharge. The paired ttest is commonly used to compare a sample group's scores before and after an intervention. Pearson correlations coefficients [rho] were calculated to search for potential relationship between QTc, HR and BMI scores and both demographic and clinical variables. All p-values lower than 0.05 were considered statistically significant.

\section{RESULTS}

Thirty consecutive patients ( 29 female) were retrospectively analyzed from January 2012 to September 2014. All were primary care referrals to a specialist unit for eating disorders (24 inpatients and 6 day care patients). Fourteen patients were on antidepressants with no effect on QTc interval $(1$ on mirtazapine $30 \mathrm{mg} / \mathrm{d}, 1$ on venlafaxine $150 \mathrm{mg} / \mathrm{d}$, and 12 on sertraline $100-150 \mathrm{mg} / \mathrm{d}$ ) due to concurrent depression [5]. 13 patients were treated using atypical antipsychotics to control OCD behavior as well as to reduce intensity of anorexic thoughts and anxiety level associated with core Eating Disorder psychopathology. Overall, atypical antipsychotics have a limited role in weight restoration and olanzapine is only drug shown conclusively to have any effect on weight restoration in AN however there is a risk of prolongation of QTc interval [7,8]. Antipsychotics were only suggested as treatment option for patients with neither personal nor family history of an abnormal heart rhythm. 5 patients were treated with olanzapine $(5-20 \mathrm{mg} /$ day $)$ and 8 were on aripiprazole, $5-15 \mathrm{mg} / \mathrm{d}$ (reported to be cardiac safe) [4].

Doses of antipsychotics used were converted into chlorpromazine equivalents [9]. Equivalent to $100 \mathrm{mg} /$ day of chlorpromazine were $5 \mathrm{mg} /$ day for olanzapine, and $5 \mathrm{pa}-$ tients on olanzapine retrospectively $400 \mathrm{mg} /$ day (1 patient) and $200 \mathrm{mg}$ /day (4 patients).

Equivalent to $100 \mathrm{mg} /$ day of chlorpromazine was $7.5 \mathrm{mg} / \mathrm{day}$ for aripiprazole giving retrospectively $133 \mathrm{mg} /$ day $(5 \mathrm{pa}-$ tients) and $200 \mathrm{mg} /$ day (3 patients).

Both antidepressants and antipsychotics were prescribed after first week of admission process. Socio-demographic and clinical data of participants are included in Table 1

\section{ECG abnormalities before treatment}

8 patients successfully reached their target BMI and the QTc interval and HR were compared in this group before and after prior to their discharge.

None of the electrocardiograms showed prolonged PR or QRS intervals. 1 patient showed T wave abnormalities and 2 patients showed prolonged QTc interval on admission. Hyponatraemia were present in 2 patients, hypokalaemia in 2 patients, hypomagnesemia in 1 patient, hypophosphatemia in 1 patient and hypocalcemia in 2 patients. Mean clinical data of patient group prior to the treatment were presented in Table 2. All inpatients were not provided with psychiatric medications at the phase of admission.

\section{ECG abnormalities after treatment}

8 patients with AN were discharged after having achieved their target BMI. The mean time interval between admission and discharge was 178 days and the mean gain in body mass was $3.91 \mathrm{~kg}$. The mean QTc interval decreased by $14 \mathrm{~ms}$ and the HR increased by 19 beats/min.

The paired t-test showed that the treatment course did elicit highly statistically significant change in HR score in individuals with $\mathrm{AN}(\mathrm{T}=-5.29, \mathrm{p}<0.001)$ (Table 2).

\section{Clinical correlates}

Pearson correlations showed that patients with a higher magnesium had lower heart rate on admission $(\mathrm{r}=-0.61$; $\mathrm{p}=0.002$ ).

Patients on atypical antipsychotics did not show any statistically significant correlations between QTc, HR, and BMI and mean antipsychotic dosage in chlorpromazine equivalents.

\section{DISCUSSION}

AN is associated with the highest mortality among all mental health disorders, attributable predominantly to cardiovascular complications such as arrhythmias [10]. Cardiac muscle atrophy, sino-atrial nodal dysfunction and bradycardia are well-known complications due to the effects of

TABLE 1. Socio-demographic and clinical characteristics of patients and control group.

\begin{tabular}{lc}
\hline \hline \multicolumn{1}{c}{ Variable } & $\begin{array}{c}\text { Anorexic patients (n=30) } \\
\text { Mean }[\text { SD] }\end{array}$ \\
\hline Age (years) & $24.33(7.51)$ \\
\hline BMI on admission $\left(\mathrm{kg} / \mathrm{m}^{2}\right)$ & $14.79(3.85)$ \\
\hline Heart rate on admission (beats/min) & $53.36(15.93)$ \\
\hline QTc interval on admission (milliseconds) & $416.22(39.92)$ \\
\hline $\begin{array}{l}\text { Sodium serum concentration } \\
\text { admission (mmol/L) }\end{array}$ & $138.20(3.58)$ \\
\hline $\begin{array}{l}\text { Potassium serum concentration } \\
\text { on admission (mmol/L) }\end{array}$ & $4.03(0.55)$ \\
\hline $\begin{array}{l}\text { Magnesium serum concentration } \\
\text { on admission (mmol/L) }\end{array}$ & $0.88(0.08)$ \\
\hline $\begin{array}{l}\text { Phosphate serum concentration level } \\
\text { on admission (mmol/L) }\end{array}$ & $1.19(0.18)$ \\
\hline $\begin{array}{l}\text { Calcium serum concentration } \\
\text { on admission (mmol/L) }\end{array}$ & $2.43(0.15)$ \\
\hline $\begin{array}{l}\text { Mean antipsychotics dosage } \\
\text { in chlorpromazine equivalent }\end{array}$ & $179.30(84.58)$ \\
\hline
\end{tabular}

TABLE 2. Clinical data from patient groups before and after treatment.

\begin{tabular}{lccc}
\hline \hline \multicolumn{1}{c}{ Variable } & $\begin{array}{c}\text { Baseline } \\
\text { Mean } \pm \text { SD }\end{array}$ & $\begin{array}{c}\text { Discharge } \\
\text { Mean } \pm \text { SD }\end{array}$ & $\begin{array}{c}\text { Test statistics } \\
\mathbf{T} ; \mathbf{d f}=\mathbf{2 9} \\
(\mathbf{P} \text { value })\end{array}$ \\
\hline BMI $\left(\mathrm{kg} / \mathrm{m}^{2}\right)$ & $14.79 \pm 3.85$ & $18.70 \pm 2.16$ & $-6.99(\mathrm{p}<0.001)$ \\
\hline HR (beats $/ \mathrm{min})$ & $53.36 \pm 15.93$ & $72.96 \pm 11.07$ & $-5.29(\mathrm{p}<0.001)$ \\
\hline QTc (milliseconds) & $416.22 \pm 39.92$ & $402.00 \pm 33.66$ & $2.01(\mathrm{p}=0.054)$ \\
\hline $\begin{array}{l}\text { T (Paired Samples Test) } \\
\text { Sig. (2-tailed) } \mathrm{p}<0.05\end{array}$ & & & \\
& & &
\end{tabular}


severe weight loss and long standing hypovolaemia [11]. Prolongation of the QTc interval, a measure of myocardial repolarization, is a biomarker for ventricular tachyarrythmias and a risk factor for sudden death [12]. In patients with AN, QTc interval abnormalities have been studied as an arrythmogenic substrate for cause sudden death and to assess effects of refeeding [13]. However, QTc interval is a relatively poor predictor of sudden cardiac death at the individual level. Only QTc intervals $>600 \mathrm{~ms}$ are clearly associated with a high risk of sudden death but patients with eating disorders rarely present with such prolonged QTc intervals [14]. In our study, the change between mean QTc at admission and discharge turned out to be statistically no significant.

Interestingly, bradycardia (mean 53 beats/min) at admission appeared a common phenomenon among our patients. This somehow was normalized after re-feeding. The pathophysiology of bradycardia in AN remains unclear but is thought to be associated with increased vagal stimulation and decreased energy metabolism due to low calorific intake [15]. It has also been postulated that bradycardia can be an offset mechanism to prevent heart failure as structural modifications do arise in AN patients whereby a decrease in left ventricular mass ensue due to malnutrition [16]. Vazque et al reported reduced glycogen content of myocardial cells and cellular atrophy that can result in bradycardia [17]. Meanwhile, bradycardia among patients with significantly low body weight can occur due to anomaly in the conduction system that may eventually require permanent pacing. However once feeding is resumed, weight restored, bradycardia is reduced and improved both at rest and during exercise [18].

AN patients may exhibit varying levels of dehydration; sodium and chloride depletion especially in patients who vomit, potassium depletion in excessive laxative users, low levels of chloride, sodium and potassium in patients abusing diuretics. Other ECG findings due to electrolyte abnormalities include $\mathrm{T}$ wave flattening or inversion $(\mathrm{K}+3.0-3.8 \mathrm{mmol} / \mathrm{L})$, long QTc interval, prominent $\mathrm{U}$ wave, ST segment depression $(\mathrm{K}+2.3-3.0 \mathrm{mmol} / \mathrm{L})$ and torsade de pointes and ventricular fibrillation $(\mathrm{K}+<2.3 \mathrm{mmol} / \mathrm{L})$ [4].

The longest measured QTc interval was $480 \mathrm{~ms}$, whereas the lowest heart rate reached 28 beats per minute. In patients at discharge, mean heart rate did significantly increase (Table 2).

QTc interval duration shortened after treatment but this appeared statistically non significant compared to QTc duration at admission. Pearson correlations between mean QTc interval at discharge and mean antipsychotic dose appeared non significant therefore the effect of atypicals on QTc interval was not established. Our study remains in line with the results published by Powers et al. who found no long QTc intervals in 15 patients either on admission or after reaching $75 \%$ of ideal body weight even if the QTc range used was 290-340 ms [19].

\section{Limitations of our study}

Our study is a single centre retrospective study and has been carried out using a relatively small sample of subjects. Besides, all the electrocardiographic measurements were done with a 12-lead ECG machine and minor beat-to-beat variations in the R-R interval that could potentially affect QTc measurements were not taken into account.

\section{CONCLUSIONS}

1. Our study found huge statistically significant improvement in mean HR of our patients after treatment. Additionally, marked improvement was recorded in patients BMI at discharge.

2. Body of literature on cardiac abnormalities in anorexia nervosa remains very limited.

3. Further exploration is needed in a larger population to investigate for etiology and other confounders that may contribute to clinical change in cardiac function throughout recovery process in patients suffering from Anorexia Nervosa and answers to the following questions:

- What is the pathophysiology of bradycardia in anorexia nervosa and how does it normalize after refeeding?

- What is the etiology and other confounders that may contribute to clinical change in cardiac function throughout recovery process in patients suffering from anorexia Nervosa?

- What specific guidelines are needed to treat cardiac abnormalities in anorexia nervosa?

\section{REFERENCES}

1. American Psychiatric Association. Diagnostic and statistical manual of mental disorders, 5th ed. Washington, DC: APA; 2013.

2. Keating C. Theoretical perspective on anorexia nervosa: The conflict of reward. Neurosci Biobehav Rev. 2010;34:73-9.

3. Birmingham CL, Treasure J. Medical management of eating disorders 2nd edition. Cambridge: Cambridge University Press; 2011.

4. Jáuregui-Garrido B, Jáuregui-Lobera I. Sudden death in eating disorders. Vasc Health Risk Manag. 2012;8:91-8.

5. NICE. Eating disorders: core interventions in the treatment and management of anorexia nervosa, bulimia nervosa and related eating disorders (NICE guideline) .Clinical guideline 9.National Institute for Health and Care Excellence.[www.nice.org.uk]

6. Royal College of Psychiatrists and Royal College of Physicians London. MARSIPAN: Management of Really Sick Patients with Anorexia Nervosa; 2010. p.20-34.

7. Taylor D, Paton C, Kapur S. The Maudsley Prescribing Guidelines 10th Edition. Informa Healthcare London; 2009

8. Leucht S, Cipriani A, Spineli L, et al.Comparative efficacy and tolerability of 15 antipsychotic drugs in schizophrenia: a multiple-treatments meta-analysis. Lancet. 2013;382(9896):951-62.

9. Woods SW. Chlorpromazine equivalent doses for the newer atypical antipsychotics. Clin Psychiatry. 2003;64(60):663-7.

10. Casiero D, Frishman WH. Cardiovascular complications of eating disorders. Cardiol Rev. 2006;14(5):227-31.

11. Mont L, Castro J, Herreros B, et al. Reversibility of cardiac abnormalities in adolescents with anorexia nerovsa after weight recovery. J Am Acad Child Adolesc Psychiatry. 2003;42(7):808-13.

12. Cooke RA, Chambers JB, Singh R, et al. QT interval in anorexia nervosa. Br Heart J. 1994;72(1):69-73.

13. Isner JM, Roberts WC, Heymsfield SB, Yager J. Anorexia nervosa and sudden death. Ann Intern Med. 1985;102(1):49-52.

14. Jackman WM, Friday KJ, Anderson JL, et al. The long QT syndromes: a critical review, new clinical observations and a unifying hypothesis. Prog Cardiovasc Dis. 1988;31(2):115-72.

15. Kollai M, Bonyhay I, Jokkel G, Szonyi L. Cardiac vagal hyperactivity in adolescent anorexia nervosa. Eur Heart J. 1994;15(8):1113-8.

16. Gottdiener JS, Gross HA, Henry WL, et al. Effects of self-induced starvation on cardiac size and function in anorexia nervosa. Circulation. 1978;58(3):425-33.

17. Vázquez M, Olivares JL, Fleta J, et al. Alteraciones cardiologicas en mujeres adolescentes con anorexia nerviosa. Rev Esp Cardiol. 2003;56(7):669-73. 
18. Olivares JL, Vázquez M, Fleta J, et al. Cardiac findings in adolescents with anorexia nervosa at diagnosis and after weight restoration. Eur $\mathrm{J}$ Pediatr. 2005;164(6):383-6.

19. Powers PS, Schocken DD, Feld J, et al. Cardiac function during weight restoration in anorexia nervosa. Int J Eat Disord. 1991;10:521-30.
Corresponding author

Dr Kevin Mohee

tel.: 01472302482

E-mail: kevin.mohee@nhs.net 